\title{
Orthopedic Treatment for Class II Malocclusion with Functional Appliances and Its Effect on Upper Airways: A Systematic Review with Meta-Analysis
}

\author{
Darius Bidjan, Rahel Sallmann, Theodore Eliades (1) and Spyridon N. Papageorgiou *(D) \\ Clinic of Orthodontics and Pediatric Dentistry, Center of Dental Medicine, University of Zurich, 8032 Zurich, \\ Switzerland; darius.bidjan@bluewin.ch (D.B.); rahel.sallmann@hotmail.com (R.S.); \\ theodore.eliades@zzm.uzh.ch (T.E.) \\ * Correspondence: snpapage@gmail.com
}

Received: 26 October 2020; Accepted: 23 November 2020; Published: 25 November 2020

check for updates

\begin{abstract}
Aim of this systematic review was to assess the effects of orthopedic treatment for Class II malocclusion with Functional Appliances (FAs) on the dimensions of the upper airways. Eight databases were searched up to October 2020 for randomized or nonrandomized clinical studies on FA treatment of Class II patients with untreated control groups. After duplicate study selection, data extraction, and risk of bias assessment according to Cochrane guidelines, random effects meta-analyses of mean differences (MDs) and their 95\% confidence intervals (CIs) were performed, followed by subgroup/meta-regression analyses and assessment of the quality of evidence. A total of 20 nonrandomized clinical studies (4 prospective/ 16 retrospective) including 969 patients ( $47.9 \%$ male; mean age 10.9 years) were identified. Orthopedic treatment with FAs was associated with increased oropharynx volume ( $\mathrm{MD}=2356.14 \mathrm{~mm}^{3} ; 95 \% \mathrm{CI}=1276.36$ to $3435.92 \mathrm{~mm}^{3} ; p<0.001$ ) compared to natural growth. Additionally, significant increases in nasopharynx volume, minimal constricted axial area of pharyngeal airway, and airway were seen, while removable FAs showed considerably greater effects than fixed FAs $(p=0.04)$. Finally, patient age and treatment duration had a significant influence in the effect of FAs on airways, as had baseline matching and sample size adequacy. Clinical evidence on orthopedic Class II treatment with FAs is associated with increased upper airway dimensions. However, the quality of evidence is very low due to methodological issues of existing studies, while the clinical relevance of increases in airway dimensions remains unclear.
\end{abstract}

Keywords: Class II malocclusion; mandibular retrognathism; orthopedic treatment; dentofacial orthopedics; orthodontics; functional appliances; clinical trials; systematic review; meta-analysis

\section{Introduction}

\subsection{Background}

Skeletal Class II malocclusion is the most common clinical entity the orthodontist is faced with [1] and is often due to a retrognathic mandible [2]. Among growing patients with a retrognathic mandible, orthopedic advancement of the mandible and its dentition with functional appliances is often performed with considerable success. However, functional appliances are now believed to have mostly dentoalveolar effects [3,4] and more limited effects on skeletal components [5-7].

At the same time, severe mandibular retrognathism has been linked to obstructive sleep apnea (OSA) [8] due to a retrodisplacement of the tongue and hyoid bone that may lead to a concomitant upper airway constriction $[9,10]$. Inversely, therapeutic advancement of the mandible with functional appliances among OSA patients has been shown to be an effective means to improve clinical OSA 
parameters [11]. Therefore, it might be reasonable to expect that functional appliance therapy among patients with skeletal Class II malocclusion might be associated with a beneficial effect on the patient's airways [12] and possibly breathing function [13].

A previous systematic review on the subject [14] concluded that early treatment with functional appliances had positive effects on the upper airway, especially on oropharyngeal dimensions, in growing skeletal Class II patients and might decrease potential risk of OSA for growing patients in the future. However, this review only covered literature published only up to the start of 2017, while its conclusions might be influenced by existing methodological issues like lack of an a priori protocol [15], incomplete handling of risk of bias within studies according to the latest Cochrane guidelines [16], issues with the data synthesis (double-counting of controls from multiarm studies, outdated statistical modelling, lack of sensitivity analyses) [17], and no assessment of the quality of meta-evidence [18]. Finally, that systematic review only assessed overall effects, did not associate them with differences between removable/fixed appliances [3,4] and did not assess any patient risk factors.

\subsection{Objective}

Therefore, the aim of this systematic review was to compare the effects of functional appliance treatment for Class II malocclusion on the upper airway dimensions with natural occurring growth in untreated Class II patients.

\section{Materials and Methods}

\subsection{Protocol, Registration, and Review Question}

This review's protocol was made a priori, registered in PROSPERO (CRD42019125897) with all post hoc changes transparently reported (Appendix A). The conduct and reporting of this review are guided by the Cochrane Handbook [19] and the PRISMA statement [20], respectively. The focused question this review tried to answer is: "Does functional appliance therapy of growing Class II patients lead to an increase in the upper airway dimensions to a degree greater than expected by natural growth alone?".

\subsection{Eligibility Criteria}

Based on the Participants-Intervention-Comparison-Outcome-Study design (PICOS) schema and as few randomized trials exist on this matter, included were randomized and nonrandomized clinical studies on systemically healthy growing human patients of any age ( $<18$ years), sex, and ethnicity with Class II malocclusion with mandibular retrognathism receiving orthopedic functional appliance treatment without any limitations on language, publication year, or status. Excluded were nonclinical studies, animal studies, and case reports/series, as well as studies with obstructive sleep apnea patients, studies without functional appliance treatment, and studies without an untreated longitudinal Class II control group. The primary outcome for this review was the total volume of the upper airways or any specific airway compartment assessed with Cone Beam Computerized Tomography (CBCT). Secondary outcomes included other measures of airway dimensions in terms of linear distances or areas, measured either on lateral cephalograms or CBCTs and in either upright or supine position.

\subsection{Information Sources and Search}

Eight electronic databases were searched without restrictions from inception to 20 October 2020 (Table S1), while ClinicalTrials.gov Directory of Open Access Journals, Digital Dissertations, metaRegister of Controlled Trials, WHO, Google Scholar, and the reference/citation lists of included articles or existing systematic reviews were manually searched. 


\subsection{Study Selection}

Two authors (D.B. and R.S.) screened the titles and/or abstracts of search hits to exclude obviously inappropriate studies, prior to checking their full texts. Any differences between the two reviewers were resolved by discussion with the last authors (T.E. and S.N.P.).

\subsection{Data Collection Process and Items}

Data from included studies was collected independently by two authors (D.B. and R.S.) with the same way to resolve discrepancies using predefined/piloted forms covering: (a) study characteristics (design, clinical setting, and country), (b) patient characteristics (age and sex), (c) eligibility criteria for patient selection, (d) treatment details (appliance and duration), and (e) outcome measurement modality.

\subsection{Risk of Bias of Individual Studies}

The risk of bias of included nonrandomized studies was assessed with a custom tool based on the ROBINS-I ("Risk Of Bias In Nonrandomized Studies-of Interventions") [16]. Assessment of the risk of bias was likewise independently performed by two authors (DB, RS) with the same approach being applied to resolve discrepancies.

\subsection{Data Synthesis and Summary Measures}

An effort was made to maximize data for the analysis; where data were missing, they were calculated by ourselves. As the outcome of upper airway dimensions is bound to be affected by patient and treatment-related characteristics (baseline dimensions, growth potential, compliance, and response to treatment), a random-effects model was a priori deemed appropriate to calculate the average distribution of true effects, based on clinical and statistical reasoning [21], and a restricted maximum likelihood variance estimator with improved performance was used according to recent guidance [22]. Mean differences (MDs) with their corresponding 95\% confidence intervals (CIs) were used, while the standardized mean difference (SMD) was decided post hoc to combine similar measurements of nasopharyngeal volume (Appendix A). The extent and impact of between-study heterogeneity was assessed by inspecting the forest plots and by calculating the tau ${ }^{2}$ (absolute heterogeneity) or the $\mathrm{I}^{2}$ statistics (relative heterogeneity). $\mathrm{I}^{2}$ defines the proportion of total variability in the result explained by heterogeneity, and not chance, while also considering the heterogeneity's direction (localization on the forest plot) and uncertainty around heterogeneity estimates [23]. The $95 \%$ random-effects predictive intervals were calculated to incorporate observed heterogeneity and predict expected results in a future treatment [24].

\subsection{Additional Analyses and Risk of Bias across Studies}

Possible sources of heterogeneity were a priori planned to be sought through random-effects subgroup analyses and meta-regressions in meta-analyses of at least five trials, according to the following factors: appliance type (removable or fixed), patient age, patient sex, and treatment duration. Reporting biases were assessed with contour-enhanced funnel plots and Egger's test [25] for meta-analyses with $\geq 10$ studies.

The overall quality of meta-evidence (i.e., the strength of clinical recommendations) was rated using the Grades of Recommendations, Assessment, Development and Evaluation (GRADE) approach [18] following recent guidance for nonrandomized studies [26]. The produced forest plots were augmented with contours denoting the magnitude of the observed effects (Appendix A) to assess heterogeneity, clinical relevance, and imprecision [17].

Robustness of the results was checked for meta-analyses $\geq 5$ studies with sensitivity analyses based on (i) the inclusion of prospective versus retrospective studies, (ii) unequal duration of treatment/observation between treated/control groups, (iii) inadequate matching (assessed with Cohen's d for baseline measurements of each outcome), and (iv) studies with inadequate versus 
inadequate samples, with the cut-off set at 25 patients/group. All analyses were run in Stata version 14.0 (StataCorp LP, College Station, TX, USA) by one author (S.N.P.) and the dataset was openly provided [27]. All $p$ values were two sided with $\alpha=5 \%$, except for the test of between-studies or between-subgroups heterogeneity where $\alpha$-value was set as $10 \%$ [28].

\section{Results}

\subsection{Study Selection}

A total of 2095 hits were retrieved by the literature database search and another 6 records were identified manually (Figure 1). After removing duplicates and eliminating nonrelevant reports by title/abstracts, 185 full-text papers were checked against the eligibility criteria (Table S2). In the end, 20 publications pertaining to 20 unique studies were included in this review.

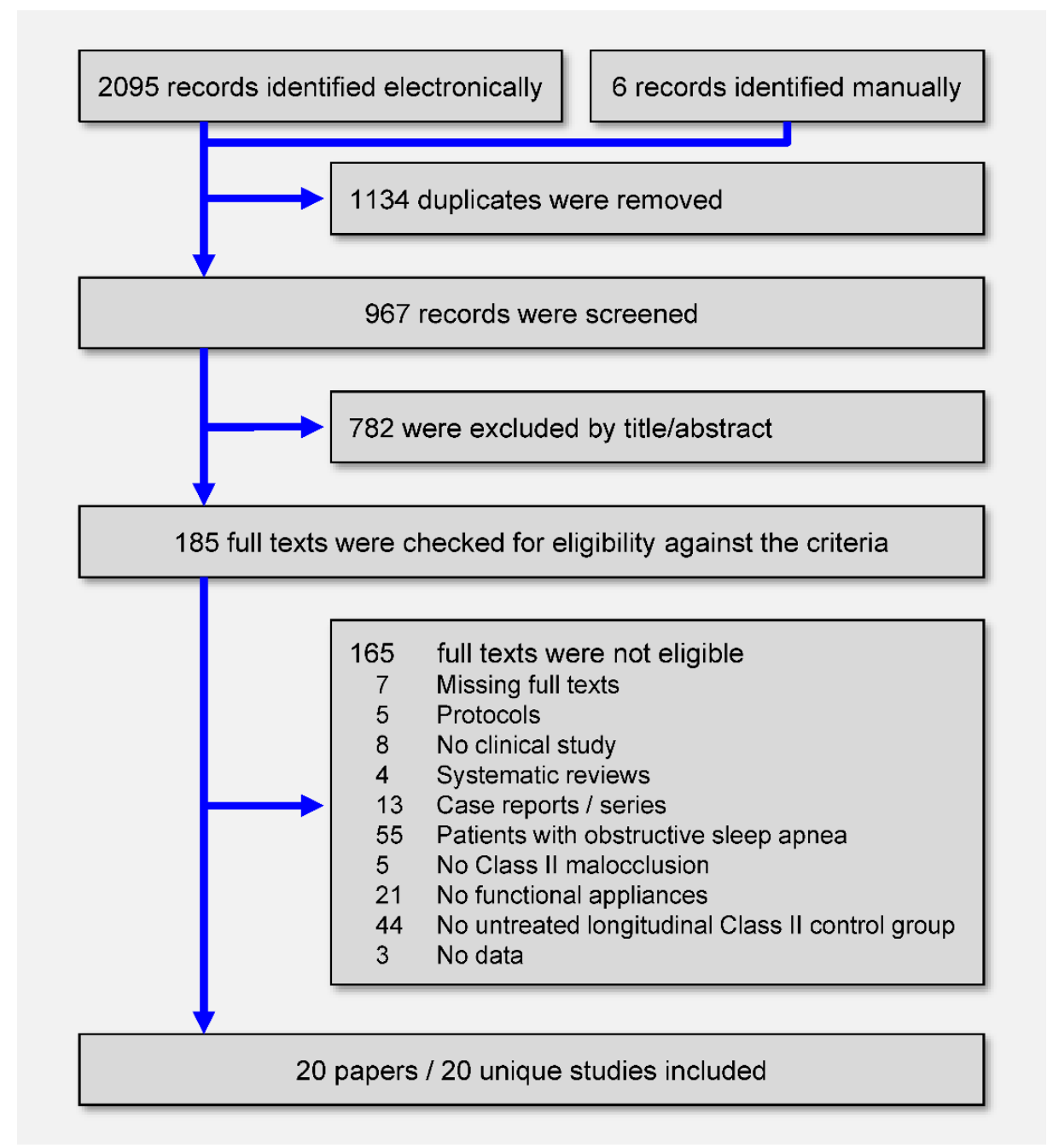

Figure 1. Preferred Reporting Items for Systematic Reviews and Meta-Analyses (PRISMA) flow diagram for the identification and selection of studies.

\subsection{Study Characteristics}

All 20 included studies [29-48] were nonrandomized (Table 1), with only 4 studies (20\%) being prospective. All studies were conducted within a university setting (one jointly with a hospital) in 9 different countries (Brazil, Egypt, India, Italy, Pakistan, Spain, Sweden, Turkey, and the United States of America). The included studies were all published as journal papers and were in English, except from one study that was in Turkish. 
Table 1. Characteristics of included studies.

\begin{tabular}{|c|c|c|c|c|}
\hline Study & Design; Setting; Country * & Patients (M/F); Age ${ }^{+}$ & Appliance (Active Duration) & Radio-Graph \\
\hline Aksu 2017 [29] & rNRS; Uni; TR & Exp: 16 (4/12); 10.3 Control: 19 (9/10); 10.2 & Exp: Activator (15.6) Control—(12.0) & Lateral ceph \\
\hline Alhammadi 2019 [30] & pNRS; Uni; EG & $\begin{array}{l}\text { Exp1: } 23(0 / 23) ; 11.9 \text { Exp2: } 21(0 / 21) ; 13.5 \\
\text { Control: } 18(0 / 18) ; 11.3\end{array}$ & $\begin{array}{l}\text { Exp1: Twin Block (Tx end) Exp2: Forsus FRD } \\
\text { (Tx end) Control—(as Exp1-2) }\end{array}$ & $\mathrm{CBCT}$ \\
\hline Ali 2015 [31] & rNRS; Uni; PK & Exp: 42 (21/21); 10.4 Control ł: 32 (16/16); 10.1 & $\begin{array}{l}\text { Exp: Twin Block +FA }(36.4) \\
\text { Control- }(36.0)\end{array}$ & Lateral ceph \\
\hline Atik 2017 [32] & rNRS; Uni; TR & $\begin{array}{l}\text { Exp1: } 15 \text { (4/11); } 8.9 \text { Exp2: } 15 \text { (6/9); } 10.6 \\
\text { Control: } 10 \text { (6/4); } 9.3\end{array}$ & $\begin{array}{l}\text { Exp1: Fränkel-2 (14.3) Exp2: X-Bow (8.6) } \\
\text { Control-(14.8) }\end{array}$ & Lateral ceph \\
\hline Bavbek 2016 [33] & rNRS; Uni; TR & Exp: 18 (10/8); 13.6 Control: 19 (8/11); 12.7 & Exp: Forsus FRD (8.7) Control—(11.9) & Lateral ceph \\
\hline Cortese 2020 [34] & rNRS; Uni; IT & Exp: $10(7 / 3) ; 10.9$ Control: 10 (5/5); 10.1 & $\begin{array}{l}\text { Exp: Activator/Twin Block (21.6) } \\
\text { Control—(40.8) }\end{array}$ & Lateral ceph \\
\hline Drosen 2018 [35] & rNRS; Uni; SE & Exp: 13 (13/0); 12.4 Control ł: 13 (13/0); 12.1 & Exp: Herbst (21.6) Control—(25.2) & Lateral ceph \\
\hline Elfeky 2015 [36] & pNRS; Uni; EG & $\begin{array}{l}\text { Exp: } 18(0 / 18) ; 10.0-12.0 \text { Control: } 18(0 / 18) \text {; } \\
10.0-12.0\end{array}$ & Exp: Twin Block (8.0) Control-(8.0) & СВСТ \\
\hline Entrenas 2019 [37] & pNRS; Uni; ES & Exp: 40 (20/20); 9.8 Control: 20 (10/10); 9.1 & $\begin{array}{l}\text { Exp: Twin Block (Tx end) } \\
\text { Control-(12.0-24.0) }\end{array}$ & Lateral ceph \\
\hline Fabiani 2017 [38] & rNRS; Uni; IT & Exp: 28 (13/15); 8.4 Control ł: 21 (14/7); 8.5 & Exp: Fränkel-2 (14.6) Control—(16.0) & Lateral ceph \\
\hline Ghodke 2014 [39] & pNRS; Uni; IN & $\begin{array}{l}\text { Exp: } 20 \text { (11/9); 8.0-13.0 Control: } 18 \text { (9/9); } \\
8.0-14.0\end{array}$ & $\begin{array}{l}\text { Exp: Twin Block (6.0) Control: } \pm \text { sectionals } \\
(6.0)\end{array}$ & Lateral ceph \\
\hline Goymen 2019 [40] & rNRS; Uni, TR & $\begin{array}{l}\text { Exp1: } 15 \text { (7/8); } 12.1 \text { Exp2: } 15 \text { (7/8); } 14.5 \\
\text { Control } \ddagger: 10 \text { (NR); } 13.0\end{array}$ & $\begin{array}{l}\text { Exp1: Twin Block (Tx end) Exp2: Forsus FRD } \\
\text { (Tx end) Control—-(6.0) }\end{array}$ & Lateral ceph \\
\hline Jena 2013 [41] & rNRS; Uni; IN & $\begin{array}{l}\text { Exp1: } 16 \text { (9/7); } 12.8 \text { Exp2: } 21 \text { (11/10); } 11.4 \\
\text { Control } 16 \text { (9/7); } 10.6\end{array}$ & $\begin{array}{l}\text { Exp1: MAPA4 (6.2) Exp2: Twin Block (9.4) } \\
\text { Control: } \pm \text { sectionals (9.9) }\end{array}$ & Lateral ceph \\
\hline Kilinc 2018 [42] & uNRS; Uni; TR & Exp: 19 (11/8); NR Control: 19 (7/12); NR & Exp: Activator (11.5) Control—(11.3) & Lateral ceph \\
\hline Oliveira 2020 [43] & rNRS; Uni; BR & Exp: 24 (15/9); NR Control: 18 (10/8); NR & Exp: Herbst (8.0) Control: Pre-Tx (10.4) & CBCT \\
\hline Ozbek 1998 [44] & rNRS; Uni; TR & Exp: 26 (11/15) 11.5 Control: 15 (7/8) 11.3 & $\begin{array}{l}\text { Exp: Activator } \pm \text { headgear }(17.4) \\
\text { Control-(23.0) }\end{array}$ & Lateral ceph \\
\hline Pavoni 2017 [45] & uNRS; Uni; IT & Exp: 51 (27/24); 9.9 Control: 31 (15/16); 10.1 & Exp: Activator (21.6) Control-(22.8) & Lateral ceph \\
\hline Rizk 2016 [46] & rNRS; Uni; US & Exp: 20 (7/13); 11.7 Control: 73 (NR); NR & Exp: MARA+FA (27.4) Control-(NR) & $\mathrm{CBCT}$ \\
\hline Rongo 2020 [47] & rNRS; Hosp/Uni; IT & Exp: 34 (21/13); 11.1 Control: 34 (25/9); 10.4 & Exp: Sander (14.8) Control一(13.9) & Lateral ceph \\
\hline Ulusoy 2014 [48] & rNRS; Uni; TR & Exp: 16 (8/8); 11.4 Control: 19 (8/11); 12.1 & Exp: Activator (11.0) Control一(11.4) & Lateral ceph \\
\hline
\end{tabular}


The eligible studies included a total of 969 patients (536 treated/433 untreated), to a median sample size of 40.5 patients/study (range: 20-93 patients/study). Among the 20 studies reporting the patients' gender, $47.9 \%$ of the patients were male ( 424 of the total 886 ), while from the 16 studies reporting mean age, the average across studies was 10.9 years (range of average age/study 8.4-14.5 years). The identified studies used dental Class II molar relationship, cephalometric skeletal anteroposterior jaw relationship, overjet, or vertical jaw configuration as eligibility criteria to include patients, while 5 studies (25\%) also included explicit reporting of no respiratory problems (Table S3). Removable functional appliances (Activator, Fränkel-2, Twin Block, or Sander appliance) were used in 16 studies, while fixed functional appliances (Herbst, Forsus Fatigue Resistant Device, Mandibular Protraction Appliance-IV, Mandibular Anterior Repositioning Appliance, or X-Bow appliance) were used in 8 studies (with 4 studies using both removable and fixed appliances). One study [32] also included a prefabricated myofunctional appliance (Trainer 4 Kids), but this was omitted from the review, due to the different modus operandi [49]. One study [44] incorporated headgear to the Activator for anchorage reinforcement, while another study [31] also included a second phase treatment with braces after a first phase with Twin Block. Airway dimensions were assessed by lateral cephalograms in $16(80 \%)$ of the studies and by CBCT in the remaining $4(20 \%)$-all of them made in an upright position. All studies reported outcome results before and after treatment with functional appliances, while only one study [35] reported long-term follow-up after treatment (6 years).

\subsection{Risk of Bias within Studies}

The risk of bias of included nonrandomized studies is summarized in Table 2 and given in detail in Table S4. For most studies, inclusion of patients in the study was not based on any factor that could influence treatment outcome ( $85 \%)$, and the treatment/control groups were clearly defined (95\%). Treated/untreated patients were explicitly reported to be selected from the same source and time in only half $(50 \%)$ of the studies, while the rate of adequate matching at baseline for potential confounders (age, sex, malocclusion, airway dimensions, and treatment/observation duration) between treated/control patients ranged from $35 \%$ to $65 \%$. Finally, no study blinded the person measuring the cephalometric/CBCT variables, while the sample size was deemed to be adequate ( $\geq 50$ patients) in $4(20 \%)$ studies. All included studies were judged to be in critical risk of bias, as issues existed for at least three domains per study.

Table 2. Risk of bias summary of included nonrandomized studies.

\begin{tabular}{cccc}
\hline Question & Yes/Probably Yes & No/Probably No & No Information \\
\hline $\begin{array}{c}\text { Was the study prospective? } \\
\text { Was selection of patients based on any factor that could }\end{array}$ & $5(25 \%)$ & $15(75 \%)$ & - \\
influence the outcome (malocclusion, airways, & $3(15 \%)$ & $17(85 \%)$ & - \\
compliance, missed appointments, breakages)? & & & \\
Were FA/CTR groups clearly defined? & $19(95 \%)$ & $1(5 \%)$ & - \\
Were FA/CTR patients treated/observed at the same & $10(50 \%)$ & $4(20 \%)$ & $6(30 \%)$ \\
$\begin{array}{c}\text { place/time? } \\
\text { Were FA/CTR patients matched for baseline age? }\end{array}$ & $11(55 \%)$ & $5(25 \%)$ & $4(20 \%)$ \\
Were FA/CTR patients matched for baseline sex? & $13(65 \%)$ & $5(25 \%)$ & $2(10 \%)$ \\
Were FA/CTR patients matched for & $12(60 \%)$ & $5(25 \%)$ & $3(15 \%)$ \\
baseline malocclusion? & $7(35 \%)$ & $13(65 \%)$ & - \\
Were FA/CTR patients matched for baseline & airway measurements? & $6(30 \%)$ & - \\
Fas the use of other appliances the same among & $14(70 \%)$ & $7(35 \%)$ & $4(20 \%)$ \\
FA/CTR patients? & $9(45 \%)$ & - & - \\
Was the observation period similar for FA/CTR patients? & $20(100 \%)$ & - & - \\
Were FA/CTR patients measured exactly the same way? & Were FA/CTR patients measured blindly? & $4(100 \%)$ & - \\
Was the adequate sample? (25 patients per group) & $4(20 \%)$ & $16(80 \%)$ & - \\
\hline
\end{tabular}

CTR, untreated control group; FA, functional appliance group. 


\subsection{Results of Individual Studies and Data Synthesis}

The results of studies not included in any meta-analyses are given in Table S5. Functional appliances were associated with a statistically significant but clinically irrelevant reduction in hypopharynx dimensions compared to untreated controls. Additionally, functional appliances were associated with statistically significant increases in nasopharynx dimensions, oropharynx cross-section, and pharynx height—with the increase in nasopharynx being also clinically relevant.

Meta-analyses of the effects of functional appliances on upper airway dimensions are given in Table 3. Orthopedic therapy with functional appliances was associated with statistically significant increases in the volume of both the nasopharynx ( 3 studies; $\mathrm{SMD}=0.95 ; 95 \% \mathrm{CI}=0.36$ to $1.54 ; p=0.002$ ) and the oropharynx (4 studies; $\mathrm{MD}=2356.14 \mathrm{~mm}^{3} ; 95 \% \mathrm{CI}=1276.36$ to $3435.92 \mathrm{~mm}^{3} ; p<0.001$; Figure 2) compared to natural growth.

Moderate heterogeneity existed among studies ( $\mathrm{I}^{2} 60 \%$ and $69 \%$, respectively), which, however, influenced only the precise quantification of the improvement seen through treatment (as all included studies were on the same side of the forest plot).

Furthermore, functional appliance therapy was associated with statistically significant increases in (i) the minimal constricted axial area of pharyngeal airway (2 studies; $\mathrm{MD}=59.91 \mathrm{~mm}^{2}$ ); (ii) superoposterior airway space ( 8 studies; $\mathrm{MD}=1.63 \mathrm{~mm}$ ); (iii) middle airway space (11 studies; $\mathrm{MD}=1.25 \mathrm{~mm}$ ); (iv) inferior airway space (10 studies; $\mathrm{MD}=1.32 \mathrm{~mm})$; (v) McNamara's lower pharynx dimension ( 3 studies; $\mathrm{MD}=2.31 \mathrm{~mm}$ ); (vi) lower adenoid thickness ( 2 studies; $\mathrm{MD}=1.16 \mathrm{~mm}$ ); and (vii) pharyngeal dimension at the epiglottal base (4 studies; $\mathrm{MD}=0.70 \mathrm{~mm}$ ). Heterogeneity was relatively moderate, except from the meta-analyses of middle and inferior airway space, where considerable heterogeneity was seen $\left(\mathrm{I}^{2}>75 \%\right)$.

\subsection{Subgroup and Meta-Regression Analyses}

Differences in the effects of removable and fixed functional appliances were assessed in Table 4 and tested formally with subgroup interaction for meta-analyses of at least 5 studies. For most outcomes, removable functional appliances showed considerable greater benefits in terms of airway dimensions than fixed appliances, like nasopharynx volume (SMDs of 1.64 and 0.73 , respectively), superoposterior airway space (MDs of 1.41 and $1.08 \mathrm{~mm}$, respectively), middle airway space (MDs of 1.37 and $1.02 \mathrm{~mm}$, respectively), and inferior airway space (MDs of 1.52 and $0.79 \mathrm{~mm}$, respectively). Additionally, increases in McNamara's lower pharynx and sagittal depth of the nasopharynx were seen only with removable functional appliances and had no significant effect with fixed functional appliances. Furthermore, an effect reversal was seen for the minimal constricted axial area of pharyngeal airway, where an increase was seen with removable appliances and a reduction was seen with fixed appliances. However, all these differences were not confirmed by formal subgroup interaction-possibly due to low statistical power. The only exception was for the primary outcome of oropharynx volume, where removable appliances induced a statistically significantly greater increase than fixed appliances (MDs of 2595.56 and $\left.2303.57 \mathrm{~mm}^{3} ; p=0.04\right)$. 
Table 3. Random-effects meta-analyses for the effect of any functional appliance versus untreated controls on airways.

\begin{tabular}{|c|c|c|c|c|c|c|}
\hline Outcome & Studies & $\operatorname{MD}(95 \% \mathrm{CI})$ & $p$ & $I^{2}(95 \%$ CI $)$ & $\begin{array}{c}\text { tau }^{2} \\
(95 \% \mathrm{CI})\end{array}$ & 95\% Prediction \\
\hline Superoposterior airway space $(\mathrm{mm})$ & 8 & $1.63(1.03,2.23)$ & $<0.001$ & $68 \%(28 \%, 92 \%)$ & $0.42(0.08,2.15)$ & $-0.13,3.39$ \\
\hline Posterior airway space $(\mathrm{mm})$ & 8 & $0.52(-0.20,1.24)$ & 0.15 & $47 \%(0 \%, 87 \%)$ & $0.44(0,3.44)$ & $-1.34,2.38$ \\
\hline Middle airway space (mm) & 11 & $1.25(0.53,1.98)$ & 0.001 & $81 \%(58 \%, 93 \%)$ & $1.09(0.36,3.69)$ & $-1.25,3.76$ \\
\hline Inferior airway space $(\mathrm{mm})$ & 10 & $1.32(0.34,2.31)$ & 0.009 & $90 \%(76 \%, 97 \%)$ & $1.97(0.75,6.47)$ & $-2.12,4.76$ \\
\hline McNamara's upper pharynx (mm) & 3 & $1.35(-0.57,3.27)$ & 0.17 & $87 \%(45 \%, 99 \%)$ & $2.45(0.31,48.50)$ & $-22.12,24.82$ \\
\hline McNamara's lower pharynx (mm) & 3 & $2.31(0.79,3.82)$ & 0.003 & $70 \%(0 \%, 99 \%)$ & $1.18(0,41.05)$ & $-14.64,19.25$ \\
\hline Upper adenoid thickness (AD2-H; mm) & 2 & $0.24(-2.10,2.58)$ & 0.84 & $93 \%(\mathrm{NE})$ & $2.65(\mathrm{NE})$ & $\mathrm{NE}$ \\
\hline Lower adenoid thickness (AD1-Ba; mm) & 2 & $1.16(0.46,1.86)$ & 0.001 & $0 \%(\mathrm{NE})$ & $0(\mathrm{NE})$ & NE \\
\hline Upper airway thickness (PNS-AD2; mm) & 5 & $0.38(-0.18,0.94)$ & 0.19 & $13 \%(0 \%, 89 \%)$ & $0.06(0,3.00)$ & $-0.81,1.57$ \\
\hline Nasopharynx height (PNS-BaN; mm) & 2 & $0.13(-0.77,1.02)$ & 0.78 & $51 \%(\mathrm{NE})$ & $0.21(\mathrm{NE}))$ & NE \\
\hline Upper pharyngeal airway passage (Ptm-UPW; mm) & 2 & $-0.37(-1.73,0.99)$ & 0.60 & $0 \%(\mathrm{NE})$ & $0(\mathrm{NE})$ & NE \\
\hline Base of epiglottis-posterior pharyngeal wall (V-LPW; mm) & 4 & $0.70(0.11,1.29)$ & 0.02 & $14 \%(0 \%, 93 \%)$ & $0.05(0,4.46)$ & $-0.93,2.33$ \\
\hline Sagittal depth of bony nasopharynx (Ba-PNS; mm) & 2 & $1.25(0.06,2.43)$ & 0.04 & $21 \%(\mathrm{NE})$ & $0.18(\mathrm{NE})$ & NE \\
\hline Minimum axial area $\left(\mathrm{mm}^{2}\right)$ & 2 & $59.91(41.46,78.35)$ & $<0.001$ & $0 \%(\mathrm{NE})$ & $0(\mathrm{NE})$ & $\mathrm{NE}$ \\
\hline Oropharynx sagittal dimension (mm) & 2 & $1.20(-2.12,4.52)$ & 0.48 & $97 \%(80 \%, 100 \%)$ & $5.58(0.68,721.82)$ & NE \\
\hline Oropharynx area (units) & $2 *$ & $556.10(-279.88,1392.08)$ & 0.19 & $0 \%(\mathrm{NE})$ & 0 (NE) & NE \\
\hline Nasopharynx volume $\left(\mathrm{mm}^{3}\right)$ & 3 & $0.95^{+}(0.36,1.54)$ & 0.002 & $60 \%(0 \%, 98 \%)$ & $0.16(0,5.02)$ & $-5.44,7.34$ \\
\hline Oropharynx volume $\left(\mathrm{mm}^{3}\right)$ & 4 & $2356.14(1276.36,3435.92)$ & $<0.001$ & $69 \%(0 \%, 98 \%)$ & $>100(0,>100)$ & $-1931.83,6644.10$ \\
\hline
\end{tabular}

$\mathrm{CI}$, confidence interval; MD, mean difference; NE, not estimable, ${ }^{*}$ Study of Ozbek 1998 omitted due to different measurement method, ${ }^{\dagger}$ SMD used instead of MD due to big differences in the control group baseline measurements. 


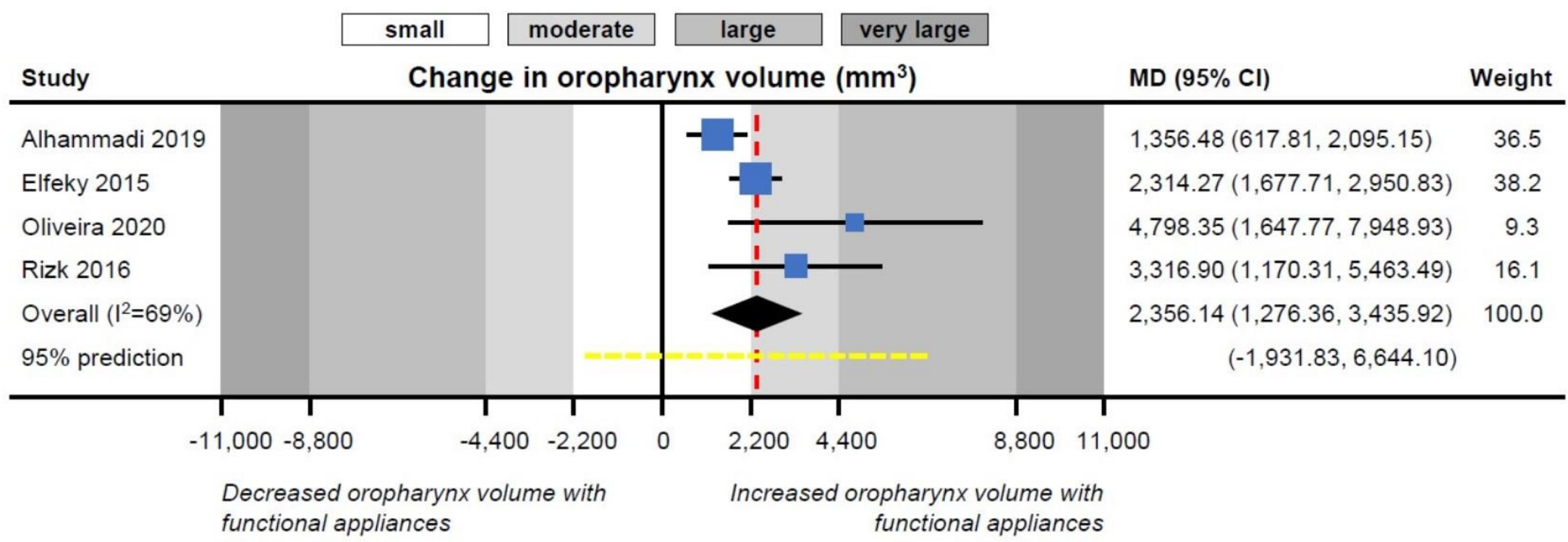

Figure 2. Contour-enhanced forest plot for the effect of functional appliances on oropharynx volume. 
Table 4. Subgroup analyses for the effect of removable or fixed functional appliances analyses versus untreated controls on airways

\begin{tabular}{|c|c|c|c|c|c|c|c|}
\hline & All Appliances & & $\begin{array}{l}\text { Removable } \\
\text { Appliances }\end{array}$ & & Fixed Appliances & & \\
\hline Outcome & MD $(95 \%$ CI $)$ & $p$ & MD $(95 \% \mathrm{CI})$ & $p$ & MD $(95 \% \mathrm{CI})$ & $p$ & $\mathbf{P}_{\mathrm{SG}}$ \\
\hline Superoposterior airway space $(\mathrm{mm})$ & $\begin{array}{c}n=8 \\
1.63(1.03,2.23)\end{array}$ & $<0.001$ & $\begin{array}{c}n=7 \\
1.41(0.65,2.17)\end{array}$ & $<0.001$ & $\begin{array}{c}n=2 \\
1.08(0.35,1.82)\end{array}$ & 0.004 & 0.20 \\
\hline Posterior airway space $(\mathrm{mm})$ & $\begin{array}{c}n=8 \\
0.52(-0.20,1.24)\end{array}$ & 0.15 & $\begin{array}{c}n=6 \\
0.83(-0.18,1.84)\end{array}$ & 0.11 & $\begin{array}{c}n=2 \\
0.14(-0.77,1.06)\end{array}$ & 0.76 & 0.35 \\
\hline Middle airway space (mm) & $\begin{array}{c}n=11 \\
1.250 .53,1.98)\end{array}$ & 0.001 & $\begin{array}{c}n=9 \\
1.37(0.47,2.26)\end{array}$ & 0.003 & $\begin{array}{c}n=3 \\
1.02(0.29,1.75)\end{array}$ & 0.006 & 0.26 \\
\hline Inferior airway space (mm) & $\begin{array}{c}n=10 \\
1.32(0.34,2.31)\end{array}$ & 0.009 & $\begin{array}{c}n=8 \\
1.52(0.32,2.72)\end{array}$ & 0.01 & $\begin{array}{c}n=2 \\
0.79(0.03,1.54)\end{array}$ & 0.04 & 0.15 \\
\hline McNamara's upper pharynx (mm) & $\begin{array}{c}n=3 \\
1.35(-0.57,3.27)\end{array}$ & 0.17 & $\begin{array}{c}n=2 \\
2.05(-0.04,4.14)\end{array}$ & 0.06 & $\begin{array}{c}n=1 \\
-0.20(-1.81,1.41)\end{array}$ & 0.81 & NT \\
\hline McNamara's lower pharynx (mm) & $\begin{array}{c}n=3 \\
2.31(0.79,3.82)\end{array}$ & 0.003 & $\begin{array}{c}n=2 \\
2.95(2.13,3.78)\end{array}$ & $<0.001$ & $\begin{array}{c}n=1 \\
0(-2.67,2.67)\end{array}$ & 1.00 & NT \\
\hline Upper adenoid thickness (AD2-H; mm) & $\begin{array}{c}n=2 \\
0.24(-2.10,2.58)\end{array}$ & 0.84 & $\begin{array}{c}n=2 \\
0.24(-2.10,2.58)\end{array}$ & 0.84 & - & & NT \\
\hline Lower adenoid thickness (AD1-Ba; mm) & $\begin{array}{c}n=2 \\
1.16(0.46,1.86)\end{array}$ & 0.001 & $\begin{array}{c}n=2 \\
1.16(0.46,1.86)\end{array}$ & 0.001 & - & & NT \\
\hline Upper airway thickness (PNS-AD2; mm) & $\begin{array}{c}n=5 \\
0.38(-0.18,0.94)\end{array}$ & 0.19 & $\begin{array}{c}n=4 \\
0.13(-0.51,0.78)\end{array}$ & 0.69 & $\begin{array}{c}n=1 \\
0.61(-1.90,3.12)\end{array}$ & 0.63 & 0.73 \\
\hline Nasopharynx height (PNS-BaN; mm) & $\begin{array}{c}n=2 \\
0.13(-0.77,1.02)\end{array}$ & 0.78 & $\begin{array}{c}n=2 \\
0.27(-1.01,1.56)\end{array}$ & 0.68 & $\begin{array}{c}n=1 \\
0.02(-0.88,0.92)\end{array}$ & 0.97 & NT \\
\hline Upper pharyngeal airway passage (Ptm-UPW; mm) & $\begin{array}{c}n=2 \\
-0.37(-1.73,0.99)\end{array}$ & 0.60 & $\begin{array}{c}\mathrm{n}=2 \\
-0.04(-1.52,1.44)\end{array}$ & 0.96 & $\begin{array}{c}n=1 \\
-1.12(-3.06,0.82)\end{array}$ & 0.26 & NT \\
\hline Base of epiglottis-posterior pharyngeal wall (V-LPW; mm) & $\begin{array}{c}n=4 \\
0.70(0.11,1.29)\end{array}$ & 0.02 & $\begin{array}{c}n=3 \\
0.65(-0.33,1.62)\end{array}$ & 0.19 & $\begin{array}{c}n=2 \\
0.51(-0.46,1.48)\end{array}$ & 0.30 & NT \\
\hline Sagittal depth of bony nasopharynx (Ba-PNS; mm) & $\begin{array}{c}n=2 \\
1.25(0.06,2.43)\end{array}$ & 0.04 & $\begin{array}{c}n=2 \\
1.62(0.57,2.68)\end{array}$ & 0.003 & $\begin{array}{c}n=1 \\
-0.71(-2.91,1.49)\end{array}$ & 0.53 & NT \\
\hline Minimum axial area $\left(\mathrm{mm}^{2}\right)$ & $\begin{array}{c}n=2 \\
59.91(41.46,78.35)\end{array}$ & $<0.001$ & $\begin{array}{c}n=2 \\
91.60(19.14 \\
197.56)\end{array}$ & 0.01 & $\begin{array}{c}n=1 \\
-26.97(-44.18,-9.76)\end{array}$ & 0.002 & NT \\
\hline Oropharynx sagittal dimension $(\mathrm{mm})$ & $\begin{array}{c}n=2 \\
1.20(-2.12,4.52)\end{array}$ & 0.48 & $\begin{array}{c}n=1 \\
-0.65(-0.89 \\
-0.42)\end{array}$ & $<0.001$ & $\begin{array}{c}n=2 \\
1.30(-1.83,4.42)\end{array}$ & 0.42 & NT \\
\hline Oropharynx area (units) & $\begin{array}{c}n=2^{*} \\
556.10(-279.88,1392.08)\end{array}$ & 0.19 & $\begin{array}{c}n=2 \\
114.35 \text { ( } 98.61 \\
130.09)\end{array}$ & $<0.001$ & $\begin{array}{c}n=1 \\
607.00(-452.17,1666.17)\end{array}$ & 0.26 & NT \\
\hline Nasopharynx volume $\left(\mathrm{mm}^{3}\right)$ & $\begin{array}{c}n=3 \\
0.95^{+}(0.36,1.54)\end{array}$ & 0.002 & $\begin{array}{c}n=1 \\
1.64^{+}(0.88,2.40)\end{array}$ & $<0.001$ & $\begin{array}{c}n=1 \\
0.73^{+}(0.10,1.36)\end{array}$ & 0.02 & NT \\
\hline Oropharynx volume $\left(\mathrm{mm}^{3}\right)$ & $\begin{array}{c}n=4 \\
2356.14(1276.36,3435.92)\end{array}$ & $<0.001$ & $\begin{array}{c}n=2 \\
2595.56(2013.07 \\
3178.05)\end{array}$ & $<0.001$ & $\begin{array}{c}n=3 \\
2303.57(-808.11,5415.25)\end{array}$ & 0.15 & 0.04 \\
\hline
\end{tabular}

$\mathrm{CI}$, confidence interval; MD, mean difference; NT, not tested; $\mathrm{P}_{\mathrm{SG}}, p$ value for subgroup differences. * Study of Ozbek 1998 omitted due to different measurement method, ${ }^{\dagger}$ SMD used instead of MD due to big differences in the control group baseline measurements. 
Meta-regression analyses indicated that patient age had a significant influence on the effects of functional appliances (Table 5), as treatment-induced increase in posterior airway space was reduced on average by $-0.36 \mathrm{~mm}(95 \% \mathrm{CI}=-0.75$ to $0.03 \mathrm{~mm})$ for each additional year of age. Additionally, a dose-response relationship was seen between increases in airway and treatment duration, as for each additional treatment month, additional increases in superoposterior airway space (coefficient $=0.12 \mathrm{~mm} ; 95 \% \mathrm{CI}=-0.02$ to $0.26 \mathrm{~mm}$ ) and inferior airway space (coefficient $=0.29 \mathrm{~mm}$; $95 \% \mathrm{CI}=0.12$ to $0.45 \mathrm{~mm}$ ) were seen. Limiting the meta-regressions to only removable functional appliances revealed a greater influence of patient's age on increases in posterior airway space (coefficient $=-0.99 \mathrm{~mm} ; 95 \% \mathrm{CI}=-1.91$ to $-0.08 \mathrm{~mm}$ ) and of treatment duration on inferior airway space (coefficient $=0.41 \mathrm{~mm} ; 95 \% \mathrm{CI}=0.26$ to $0.56 \mathrm{~mm}$ ), which might be anticipated, due to the greater treatment effects of removable appliances on the airways.

Table 5. Meta-regression analysis on the effect of functional appliances on airways.

\begin{tabular}{|c|c|c|c|c|c|c|}
\hline \multirow[b]{2}{*}{ Outcome } & \multicolumn{3}{|c|}{$\begin{array}{l}\text { Any Functional Appliance } \\
\text { (Removable/Fixed) }\end{array}$} & \multicolumn{3}{|c|}{ Only Removable Appliances } \\
\hline & $\begin{array}{l}\text { Patient Age } \\
\text { (Per Year) }\end{array}$ & $\begin{array}{l}\text { Male \% in } \\
\text { Sample } \\
\text { (Per \%) }\end{array}$ & $\begin{array}{c}\text { Treatment } \\
\text { Duration } \\
\text { (Per Month) }\end{array}$ & $\begin{array}{l}\text { Patient Age } \\
\text { (Per Year) }\end{array}$ & $\begin{array}{l}\text { Male \% in } \\
\text { Sample } \\
(\text { Per \%) }\end{array}$ & $\begin{array}{l}\text { Treatment } \\
\text { Duration } \\
\text { (Per Month) }\end{array}$ \\
\hline $\begin{array}{l}\text { Upper airway thickness } \\
\text { (PNS-AD2; mm) }\end{array}$ & $\begin{array}{c}\mathrm{b}=-0.55 \\
p=0.30\end{array}$ & $\begin{array}{c}\mathrm{b}=-4.03 \\
p=0.43\end{array}$ & $\begin{array}{l}\mathrm{b}=0.03 \\
p=0.26\end{array}$ & NT & $\begin{array}{c}\mathrm{b}=-4.71 \\
p=0.46\end{array}$ & NT \\
\hline $\begin{array}{l}\text { Superoposterior airway } \\
\text { space }(\mathrm{mm})\end{array}$ & $\begin{array}{l}\mathrm{b}=0.11 \\
p=0.69\end{array}$ & $\begin{array}{l}\mathrm{b}=1.99 \\
p=0.47\end{array}$ & $\begin{array}{l}\mathrm{b}=0.12 \\
p=0.09\end{array}$ & $\begin{array}{l}\mathrm{b}=0.41 \\
p=0.41\end{array}$ & $\begin{array}{l}\mathrm{b}=2.13 \\
p=0.49\end{array}$ & $\begin{array}{l}\mathrm{b}=0.17 \\
p=0.12\end{array}$ \\
\hline $\begin{array}{l}\text { Posterior airway } \\
\text { space }(\mathrm{mm})\end{array}$ & $\begin{array}{c}\mathrm{b}=-0.36 \\
p=0.06\end{array}$ & $\begin{array}{c}\mathrm{b}=-6.00 \\
p=0.15\end{array}$ & $\begin{array}{l}\mathrm{b}=0.07 \\
p=0.45\end{array}$ & $\begin{array}{c}\mathrm{b}=-0.99 \\
p=0.04\end{array}$ & $\begin{array}{c}\mathrm{b}=-6.15 \\
p=0.24\end{array}$ & $\begin{array}{l}\mathrm{b}=0.07 \\
p=0.70\end{array}$ \\
\hline Middle airway space (mm) & $\begin{array}{l}\mathrm{b}=0.03 \\
p=0.91\end{array}$ & $\begin{array}{l}\mathrm{b}=-2.59 \\
p=0.41\end{array}$ & $\begin{array}{l}\mathrm{b}=0.09 \\
p=0.28\end{array}$ & $\begin{array}{l}\mathrm{b}=0.10 \\
p=0.84\end{array}$ & $\begin{array}{c}\mathrm{b}=-3.40 \\
p=0.37\end{array}$ & $\begin{array}{l}\mathrm{b}=0.09 \\
p=0.48\end{array}$ \\
\hline Inferior airway space (mm) & $\begin{array}{c}\mathrm{b}=-0.13 \\
p=0.78\end{array}$ & $\begin{array}{l}\mathrm{b}=1.56 \\
p=0.71\end{array}$ & $\begin{array}{l}\mathrm{b}=0.29 \\
p=0.003\end{array}$ & $\begin{array}{l}\mathrm{b}=0.02 \\
p=0.98\end{array}$ & $\begin{array}{l}\mathrm{b}=1.61 \\
p=0.73\end{array}$ & $\begin{array}{c}\mathrm{b}=0.41 \\
p<0.001\end{array}$ \\
\hline $\begin{array}{c}\text { Base of epiglottis-posterior } \\
\text { pharyngeal wall } \\
\text { (V-LPW; mm) }\end{array}$ & $\begin{array}{l}\mathrm{b}=0.29 \\
p=0.46\end{array}$ & $\begin{array}{c}\mathrm{b}=-12.09 \\
p=0.41\end{array}$ & $\begin{array}{c}\mathrm{b}=-0.13 \\
p=0.38\end{array}$ & NT & $\begin{array}{c}\mathrm{b}=-13.62 \\
p=0.55\end{array}$ & NT \\
\hline Oropharynx volume $\left(\mathrm{mm}^{3}\right)$ & $\begin{array}{c}\mathrm{b}=-1256.28 \\
p=0.17\end{array}$ & $\begin{array}{c}\mathrm{b}=5027.43 \\
p=0.23\end{array}$ & $\begin{array}{c}\mathrm{b}=13.37 \\
p=0.92\end{array}$ & NT & NT & NT \\
\hline
\end{tabular}

$\mathrm{b}$, meta-regression coefficient; NT, not tested (as less than 5 studies contributed to the analysis).

\subsection{Reporting Biases and Sensitivity Analyses}

Reporting biases (including the possibility for publication bias) could be assessed only for the meta-analyses of middle and inferior airway space that included at least 10 studies. The funnel plots (Figure S1) indicated asymmetry, which was confirmed by Egger's test in both instances $(p=0.07$ and $p=0.006$, respectively). However, this was interpreted as small-study effects, with smaller/more imprecise studies reporting greater treatment effects than larger studies.

Sensitivity analyses according to methodological issues of existing studies are seen in Table 6. No significant differences in the meta-analyses were seen between prospective versus retrospective studies nor according to the difference between treatment and observation durations. However, adequate baseline matching had a significant effect on the reported treatment effects of functional appliances. Studies with greater baseline differences between treated/untreated patients (i.e., without adequate matching) reported significantly greater increases in middle (coefficient $=0.93$ $\mathrm{mm}$ ) and posterior airway space (coefficient $=1.86 \mathrm{~mm}$ ). Furthermore, studies with adequate sample size ( $\geq 50$ patients) reported significantly higher increases of inferior airway space (coefficient $=2.05$ $\mathrm{mm}$ ) compared to smaller studies. Therefore, future clinical recommendations should be based on studies with adequate baseline matching (preferably through randomization) and with adequate sample size. 
Table 6. Sensitivity analyses on the effect of methodological characteristics on the effect of functional appliances on airways.

\begin{tabular}{|c|c|c|c|c|}
\hline Outcome & $\begin{array}{l}\text { Prospective Vs } \\
\text { Retrospective } \\
\text { (Ref) }\end{array}$ & $\begin{array}{l}\text { Tx-Ctr Difference } \\
\text { in Duration (Per } \\
\text { Month) }\end{array}$ & $\begin{array}{l}\text { Tx-Ctr Difference in } \\
\text { Baseline Outcome (In } \\
\text { Absolute Cohen's d) }\end{array}$ & $\begin{array}{c}\text { Adequate Sample } \\
(\geq 50) \text { vs. } \\
\text { Inadequate (Ref) }\end{array}$ \\
\hline Upper airway thickness (PNS-AD2; mm) & $\mathrm{NE}$ & $\begin{array}{l}\mathrm{b}=0.05 \\
p=0.82\end{array}$ & $\begin{array}{l}\mathrm{b}=0.38 \\
p=0.26\end{array}$ & $\begin{array}{l}\mathrm{b}=0.39 \\
p=0.59\end{array}$ \\
\hline Superoposterior airway space $(\mathrm{mm})$ & NE & $\begin{aligned} \mathrm{b} & =-0.07 \\
p & =0.32\end{aligned}$ & $\begin{array}{l}\mathrm{b}=0.82 \\
p=0.15\end{array}$ & $\begin{array}{l}\mathrm{b}=0.91 \\
p=0.36\end{array}$ \\
\hline Posterior airway space $(\mathrm{mm})$ & NE & $\begin{array}{l}\mathrm{b}=0.04 \\
p=0.83\end{array}$ & $\begin{array}{l}\mathrm{b}=1.86 \\
p=0.08\end{array}$ & $\begin{array}{c}\mathrm{b}=-0.46 \\
p=0.65\end{array}$ \\
\hline Middle airway space $(\mathrm{mm})$ & $\begin{array}{c}\mathrm{b}=-0.65 \\
p=0.62\end{array}$ & $\begin{array}{l}\mathrm{b}=0.01 \\
p=0.91\end{array}$ & $\begin{array}{l}\mathrm{b}=0.93 \\
p=0.04\end{array}$ & $\begin{array}{c}\mathrm{b}=-1.56 \\
p=0.27\end{array}$ \\
\hline Inferior airway space $(\mathrm{mm})$ & $\mathrm{NE}$ & $\begin{array}{c}\mathrm{b}=-0.03 \\
p=0.79\end{array}$ & $\begin{array}{l}\mathrm{b}=0.51 \\
p=0.64\end{array}$ & $\begin{array}{l}\mathrm{b}=2.05 \\
p=0.09\end{array}$ \\
\hline $\begin{array}{l}\text { Base of epiglottis-posterior pharyngeal } \\
\text { wall (V-LPW; mm) }\end{array}$ & $\begin{array}{l}\mathrm{b}=0.95 \\
p=0.26\end{array}$ & $\begin{array}{l}\mathrm{b}=0.03 \\
p=0.90\end{array}$ & $\begin{array}{c}\mathrm{b}=-0.48 \\
p=0.60\end{array}$ & $\begin{array}{c}\mathrm{b}=-1.45 \\
p=0.29\end{array}$ \\
\hline Oropharynx volume $\left(\mathrm{mm}^{3}\right)$ & $\begin{array}{c}\mathrm{b}=-2334.16 \\
p=0.27\end{array}$ & $\mathrm{NE}$ & $\begin{aligned} \mathrm{b} & =-3586.53 \\
p & =0.36\end{aligned}$ & $\begin{array}{c}\mathrm{b}=-1406.38 \\
p=0.51\end{array}$ \\
\hline
\end{tabular}

b, meta-regression coefficient; Ctr, control; NE, not estimable; Ref, reference; Tx, treatment.

\subsection{Quality of Evidence}

The quality of evidence according to GRADE was very low in all instances (downgraded by two points), due to the lack of randomization and the many methodological issues from the identified retrospective studies that might introduce bias. Therefore, our confidence in current estimates is very low and future studies might change current recommendations.

\section{Discussion}

\subsection{Evidence in Context}

The present systematic review summarizes clinical evidence from existing studies assessing the effects of Class II orthopedic treatment with functional appliances on airway dimensions to untreated Class II controls. A total of 20 studies including 536 treated and 433 untreated Class II patients were finally included in the meta-analyses.

Mandibular advancement with removable or fixed functional appliances was associated with statistically significant increases in airway dimensions directly after treatment compared to what could be expected by Class II growth alone. Specifically, benefits were seen for volume of the naso- and oropharynx, the minimal constricted axial area of pharyngeal airway, and many sagittal measurements of the oropharynx (Table 3). However, many of these changes, especially at the upper pharynx, were small to moderate in magnitude, which means that they might have little clinical relevance. On the contrary, greater effects were seen at the lower part of the pharynx and this indicates that any clinically relevant benefits in airway dimensions or breathing might be attributed in this compartment. There is some evidence indicating that normal patients and patients with sleep-disordered breathing have significant differences in the dimensions of the pharyngeal airway or the thickness of the pharyngeal wall [50], and the lower retropalatal/retroglossal areas are mostly affected [51]. This area has also emerged as a sensitive parameter enabling to consistently assess the patient's respiratory conditions [52]. However, even though increases in airway volume or cross-section might be indicative of improved breathing, functional confirmation through improved nasal airflow resistance, nasal pressure, and patient-relevant outcomes is needed. Some data indicate that treatment with Herbst appliance improved nocturnal breathing in adolescents [53], but the evidence is weak due to the lack of a control group and further studies are needed.

The exact mechanism with which these changes on the upper airway occur is currently unknown, but it might be that the mesial displacement of the lower dentition and the labial flaring of the lower incisors, might cause anterior traction on the tongue and hyoid bone [48], thereby causing adaptive 
changes of the soft palate and leading to an increase in pharyngeal airway dimensions [33]. This is also compatible with the observation that the soft palate is anteriorly repositioned after functional appliance treatment of Class II $[39,41]$ as the tongue moves away from the palate. However, confirmatory studies are needed.

The effects of orthopedic mandibular advancement on the airways were highly variable among the included studies, which was reflected in between-study heterogeneity. Part of this heterogeneity was explained by several patient- or treatment-related characteristics including patient age, appliance design, and treatment duration (Tables 4 and 5). Removable functional appliances were shown to exert greater changes in the upper airway dimensions than fixed appliances for most of the analyzed variables. This might be due to different skeletal/dentoalveolar effects of removable/fixed appliances that have been previously reported [4]. On the other hand, this might be due to the fact that fixed functional appliances are usually placed on older patients after most deciduous teeth have been shed, whereas removable functional appliances are often placed in the mixed dentition (an age difference also seen among the included studies). This might act as a confounding factor at least to some part, since patient age was consistently associated with the observed airway benefits, both for the whole set of included studies and, specifically, for the subset of removable appliances (Table 5). It is generally believed that, moreover, skeletal effects of functional appliances are more pronounced in patients treated before or during the growth peak [54].

Existing clinical studies only demonstrated the short-term beneficial effect of functional appliances on the upper airways. However, it remains to be seen whether such benefits remain stable in the long term. The sole included study assessing long-term status of treated Class II patients [35] indicated that not only were the benefits of functional appliance treatment retained 6 years afterwards, but a significantly greater post-treatment increase was seen. This is also consistent with previous evidence on the long-term stability of increased airway dimensions among patients with skeletal Class III treated orthopedically with maxillary protraction [55].

\subsection{Strengths and Limitations}

Among the strengths of the current review can be counted it is a priori registration [15], the extensive searching of the literature, the inclusion of untreated Class II controls, the use of contemporary statistical methods [22], the gauging of the quality of meta-evidence according to GRADE [18], and the transparent open provision of the dataset [56].

On the other hand, some limitations also exist, like the inclusion of weak study designs like retrospective nonrandomized studies [57] with historical controls [58], which might introduce bias. Additionally, most studies had small sample sizes and this can affect the precision of the estimated effects [59]. Moreover, many included studies were inadequately matched in terms of similar baseline airway dimensions, and baseline dissimilarities were associated with inflated treatment effects (Table 6), which is in agreement with previous meta-epidemiological evidence $[60,61]$. Furthermore, airways before and after treatment were assessed with radiographs done in the upright position and not in a supine position, since most studies were retrospective with nonapneic patients that received functional appliance treatment for their underlying malocclusion and airways were only secondarily assessed. However, changes between supine or upright posture can influence airways measurements [62-64], even though oropharyngeal area measurement from lateral cephalograms can be used as an initial screening measurement to predict the upright upper airway 3D volume [64]. Finally, the small number and the limited reporting of existing studies did not enable extensive subgroup and meta-regression analyses to identify and account for sources of confounding, like patient age, sex, growth pattern, and presence/size of tonsils or adenoid, which might influence the observed results. Further prospective, ideally randomized, studies with open provision of their full dataset [56] will help in shedding on the pure airway effects of orthopedic treatment for Class II malocclusion. 


\section{Conclusions}

Current evidence indicates that orthopedic treatment with functional appliances for Class II malocclusion might be associated with increased volume and dimensions of the upper airways, which are dependent on patient- and treatment-related factors. However, our confidence in these data is very low due to the poor quality of existing studies and their small number. It is crucial that the clinical relevance of such anatomical changes is confirmed by functional analyses of breathing ability before concrete recommendations can be formulated.

Supplementary Materials: The following are available online at http://www.mdpi.com/2077-0383/9/12/3806/ s1, Figure S1: Contour-enhanced funnel plots for assessing reporting biases and publication bias; Table S1: Literature searches with resulting hits (last search date: 20 October 2020); Table S2: List of studies identified from the literature search and their inclusion/exclusion status, with reasons; Table S3: Malocclusion characteristics of the patients within the included studies; Table S4: Detailed risk of bias of included nonrandomized studies; Table S5: Results of individual studies not included in meta-analyses.

Author Contributions: D.B., T.E. and S.N.P. developed the research protocol. D.B. and R.S. independently performed study selection in duplicate, data extraction, and risk of bias assessment. Disagreements were resolved with the last authors (T.E. and S.N.P.). Literature searches analysis were performed by the first author (D.B.) and data analysis was performed by the last author (S.N.P.). All authors (D.B., R.S., T.E. and S.N.P.) read and approved the final manuscript. All authors have read and agreed to the published version of the manuscript.

Funding: This research received no external funding.

Conflicts of Interest: The authors declare no conflict of interest.

\section{Appendix A}

Additional details of methods and deviations from protocol.

Additional method details:

- When before-and-after treatment values were provided, these were converted to treatment-induced increments (post minus pre) according to Cochrane guidelines assuming a pre/post correlation of 0.75 [19].

- The produced forest plots were augmented with contours denoting the magnitude of expected effects: small (up to half a Standard Deviation [SD]), moderate (half to one SD), large (one to two SDs) and very large (more than 2 SDs). The SD for each outcome's forest plot was based on the average pre-treatment $\mathrm{SD}$ of the response variable across all eligible studies for each meta-analysis (rounded up to 2 decimals).

Post hoc changes:

- The standardized mean difference was chosen over the mean difference for the meta-analysis of nasopharynx volume since considerable differences were seen among the measurements of the included studies (one study reporting baseline volume in the control group being twice as large as the volume in the other two studies).

\section{References}

1. Josefsson, E.; Bjerklin, K.; Lindsten, R. Malocclusion frequency in Swedish and immigrant adolescents-Influence of origin on orthodontic treatment need. Eur. J. Orthod. 2007, 29, 79-87. [CrossRef] [PubMed]

2. McNamara, J.A., Jr. Components of class II malocclusion in children 8-10 years of age. Angle Orthod. 1981, 51, 177-202. [CrossRef] [PubMed]

3. Koretsi, V.; Zymperdikas, V.F.; Papageorgiou, S.N.; Papadopoulos, M.A. Treatment effects of removable functional appliances in patients with Class II malocclusion: A systematic review and meta-analysis. Eur. J. Orthod. 2015, 37, 418-434. [CrossRef] [PubMed]

4. Zymperdikas, V.F;; Koretsi, V.; Papageorgiou, S.N.; Papadopoulos, M.A. Treatment effects of fixed functional appliances in patients with Class II malocclusion: A systematic review and meta-analysis. Eur. J. Orthod. 2016, 38, 113-126. [CrossRef] 
5. Franchi, L.; Pavoni, C.; Faltin, K., Jr.; McNamara, J.A., Jr.; Cozza, P. Long-term skeletal and dental effects and treatment timing for functional appliances in Class II malocclusion. Angle Orthod. 2013, 83, 334-340. [CrossRef]

6. Batista, K.B.; Thiruvenkatachari, B.; Harrison, J.E.; O’Brien, K.D. Orthodontic treatment for prominent upper front teeth (Class II malocclusion) in children and adolescents. Cochrane Database Syst. Rev. 2018, 3, CD003452. [CrossRef]

7. Kyburz, K.S.; Eliades, T.; Papageorgiou, S.N. What effect does functional appliance treatment have on the temporomandibular joint? A systematic review with meta-analysis. Prog. Orthod. 2019, 20, 32. [CrossRef]

8. Arens, R.; Marcus, C.L. Pathophysiology of upper airway obstruction: A developmental perspective. Sleep 2004, 27, 997-1019. [CrossRef]

9. Schellenberg, J.B.; Maislin, G.; Schwab, R.J. Physical findings and the risk for obstructive sleep apnea. The importance of oropharyngeal structures. Am. J. Respir. Crit. Care Med. 2000, 162, 740-748. [CrossRef]

10. Claudino, L.V.; Mattos, C.T.; Ruellas, A.C.; Sant' Anna, E.F. Pharyngeal airway characterization in adolescents related to facial skeletal pattern: A preliminary study. Am. J. Orthod. Dentofac. Orthop. 2013, 143, 799-809. [CrossRef]

11. Koretsi, V.; Eliades, T.; Papageorgiou, S.N. Oral Interventions for Obstructive Sleep Apnea. Dtsch. Arztebl. Int. 2018, 115, 200-207. [CrossRef] [PubMed]

12. Lanteri, V.; Farronato, M.; Ugolini, A.; Cossellu, G.; Gaffuri, F.; Parisi, F.M.R.; Cavagnetto, D.; Abate, A.; Maspero, C. Volumetric Changes in the Upper Airways after Rapid and Slow Maxillary Expansion in Growing Patients: A Case-Control Study. Materials 2020, 13, 2239. [CrossRef] [PubMed]

13. Shete, C.S.; Bhad, W.A. Three-dimensional upper airway changes with mandibular advancement device in patients with obstructive sleep apnea. Am. J. Orthod. Dentofac. Orthop. 2017, 151, 941-948. [CrossRef] [PubMed]

14. Xiang, M.; Hu, B.; Liu, Y.; Sun, J.; Song, J. Changes in airway dimensions following functional appliances in growing patients with skeletal class II malocclusion: A systematic review and meta-analysis. Int. J. Pediatr. Otorhinolaryngol. 2017, 97, 170-180. [CrossRef]

15. Sideri, S.; Papageorgiou, S.N.; Eliades, T. Registration in the international prospective register of systematic reviews (PROSPERO) of systematic review protocols was associated with increased review quality. J. Clin. Epidemiol. 2018, 100, 103-110. [CrossRef]

16. Sterne, J.A.; Hernán, M.A.; Reeves, B.C.; Savović, J.; Berkman, N.D.; Viswanathan, M.; Henry, D.; Altman, D.G.; Ansari, M.T.; Boutron, I.; et al. ROBINS-I: A tool for assessing risk of bias in non-randomised studies of interventions. BMJ 2016, 355, i4919. [CrossRef]

17. Papageorgiou, S.N. Meta-analysis for orthodontists: Part II-Is all that glitters gold? J. Orthod. 2014, 41, 327-336. [CrossRef]

18. Guyatt, G.H.; Oxman, A.D.; Schünemann, H.J.; Tugwell, P.; Knottnerus, A. GRADE guidelines: A new series of articles in the Journal of Clinical Epidemiology. J. Clin. Epidemiol. 2011, 64, 380-382. [CrossRef]

19. Higgins, J.P.T.; Green, S. Cochrane Handbook for Systematic Reviews of Interventions Version 5.1.0; The Cochrane Collaboration: London, UK, 2011.

20. Liberati, A.; Altman, D.G.; Tetzlaff, J.; Mulrow, C.; Gøtzsche, P.C.; Ioannidis, J.P.A.; Clarke, M.; Devereaux, P.J.; Kleijnen, J.; Moher, D. The PRISMA statement for reporting systematic reviews and meta-analyses of studies that evaluate health care interventions: Explanation and elaboration. J. Clin. Epidemiol. 2009, 62, e1-e34. [CrossRef]

21. Papageorgiou, S.N. Meta-analysis for orthodontists: Part I-How to choose effect measure and statistical model. J. Orthod. 2014, 41, 317-326. [CrossRef]

22. Langan, D.; Higgins, J.P.T.; Jackson, D.; Bowden, J.; Veroniki, A.A.; Kontopantelis, E.; Viechtbauer, W.; Simmonds, M. A comparison of heterogeneity variance estimators in simulated random-effects meta-analyses. Res. Synth. Methods 2019, 10, 83-98. [CrossRef] [PubMed]

23. Higgins, J.P.T.; Thompson, S.G.; Deeks, J.J.; Altman, D.G. Measuring inconsistency in meta-analyses. BMJ 2003, 327, 557-560. [CrossRef] [PubMed] 
24. IntHout, J.; Ioannidis, J.P.A.; Rovers, M.M.; Goeman, J.J. Plea for routinely presenting prediction intervals in meta-analysis. BMJ Open 2016, 6, e010247. [CrossRef]

25. Egger, M.; Davey Smith, G.; Schneider, M.; Minder, C. Bias in meta-analysis detected by a simple, graphical test. BMJ 1997, 315, 629-634. [CrossRef] [PubMed]

26. Schünemann, H.J.; Cuello, C.; Akl, E.A.; Mustafa, R.A.; Meerpohl, J.J.; Thayer, K.; Morgan, R.L.; Gartlehner, G.; Kunz, R.; Katikireddi, S.V.; et al. GRADE guidelines: 18. How ROBINS-I and other tools to assess risk of bias in nonrandomized studies should be used to rate the certainty of a body of evidence. J. Clin. Epidemiol. 2019, 111, 105-114. [CrossRef] [PubMed]

27. Bidjan, D.; Sallmann, R.; Eliades, T.; Papageorgiou, S.N. Orthopedic treatment for Class II malocclusion with functional appliances and its effect on upper airways: A systematic review with meta-analysis [dataset]. Zenodo 2020. [CrossRef]

28. Ioannidis, J.P.A. Interpretation of tests of heterogeneity and bias in meta-analysis. J. Eval. Clin. Pract. 2008, 14, 951-957. [CrossRef]

29. Aksu, M.; Gorucu-Coskuner, H.; Taner, T. Assessment of upper airway size after orthopedic treatment for maxillary protrusion or mandibular retrusion. Am. J. Orthod. Dentofac. Orthop. 2017, 152, 364-370. [CrossRef]

30. Alhammadi, M.S.; Elfeky, H.Y.; Fayed, M.S.; Ishaq, R.A.R.; Halboub, E.; Al-Mashraqi, A.A. Three-dimensional skeletal and pharyngeal airway changes following therapy with functional appliances in growing skeletal Class II malocclusion patients: A controlled clinical trial. J. Orofac. Orthop. 2019, 80, 254-265. [CrossRef]

31. Ali, B.; Shaikh, A.; Fida, M. Effect of Clark's twin-block appliance (CTB) and non-extraction fixed mechano-therapy on the pharyngeal dimensions of growing children. Dent. Press J. Orthod. 2015, 20, 82-88. [CrossRef]

32. Atik, E.; Gorucu-Coskuner, H.; Kocadereli, I. Dentoskeletal and airway effects of the X-Bow appliance versus removable functional appliances (Frankel-2 and Trainer) in prepubertal Class II division 1 malocclusion patients. Aust. Orthod. J. 2017, 33, 3-13.

33. Bavbek, N.C.; Tuncer, B.B.; Turkoz, C.; Ulusoy, C.; Tuncer, C. Changes in airway dimensions and hyoid bone position following class II correction with forsus fatigue resistant device. Clin. Oral Investig. 2016, 20, 1747-1755. [CrossRef] [PubMed]

34. Cortese, M.; Pigato, G.; Casiraghi, G.; Ferrari, M.; Bianco, E.; Maddalone, M. Evaluation of the Oropharyngeal Airway Space in Class II Malocclusion Treated with Mandibular Activator: A Retrospective Study. J. Contemp. Dent. Pract. 2020, 21, 666-672. [PubMed]

35. Drosen, C.; Bock, N.C.; von Bremen, J.; Pancherz, H.; Ruf, S. Long-term effects of Class II Herbst treatment on the pharyngeal airway width. Eur. J. Orthod. 2018, 40, 82-89. [CrossRef] [PubMed]

36. Elfeky, H.Y.; Fayed, M.M.S. Three-dimensional effects of twin block therapy on pharyngeal airway parameters in Class II malocclusion patients. J. World Fed. Orthod. 2015, 4, 114-119. [CrossRef]

37. Entrenas, I.; González-Chamorro, E.; Álvarez-Abad, C.; Muriel, J.; Menéndez-Díaz, I.; Cobo, T. Evaluation of changes in the upper airway after Twin Block treatment in patients with Class II malocclusion. Clin. Exp. Dent. Res. 2019, 5, 259-268. [CrossRef] [PubMed]

38. Fabiani, G.; Galván Galván, J.; Raucci, G.; Elyasi, M.; Pachêco-Pereira, C.; Flores-Mir, C.; Perillo, L. Pharyngeal airway changes in pre-pubertal children with Class II malocclusion after Frankel-2 treatment. Eur. J. Paediatr. Dent. 2017, 18, 291-295. [CrossRef] [PubMed]

39. Ghodke, S.; Utreja, A.K.; Singh, S.P.; Jena, A.K. Effects of twin-block appliance on the anatomy of pharyngeal airway passage (PAP) in class II malocclusion subjects. Prog. Orthod. 2014, 15, 68. [CrossRef]

40. Göymen, M.; Mourad, D.; Güleç, A. Evaluation of Airway Measurements in Class II Patients Following Functional Treatment. Turk. J. Orthod. 2019, 32, 6-10. [CrossRef]

41. Jena, A.K.; Singh, S.P.; Utreja, A.K. Effectiveness of twin-block and Mandibular Protraction Appliance-IV in the improvement of pharyngeal airway passage dimensions in Class II malocclusion subjects with a retrognathic mandible. Angle Orthod. 2013, 83, 728-734. [CrossRef]

42. Kilinc, D.D.; Sayar, G. Pharyngeal airway changes of patients after Class II activator treatment. Selcuk Dent. J. 2018, 5, 8-12. [CrossRef] 
43. Oliveira, P.M.; Cheib-Vilefort, P.L.; de Pársia Gontijo, H.; Melgaço, C.A.; Franchi, L.; McNamara, J.A., Jr.; Souki, B.Q. Three-dimensional changes of the upper airway in patients with Class II malocclusion treated with the Herbst appliance: A cone-beam computed tomography study. Am. J. Orthod. Dentofac. Orthop. 2020, 157, 205-211. [CrossRef]

44. Ozbek, M.M.; Memikoglu, T.U.; Gogen, H.; Lowe, A.A.; Baspinar, E. Oropharyngeal airway dimensions and functional-orthopedic treatment in skeletal Class II cases. Angle Orthod. 1998, 68, 327-336. [CrossRef] [PubMed]

45. Pavoni, C.; Cretella Lombardo, E.; Franchi, L.; Lione, R.; Cozza, P. Treatment and post-treatment effects of functional therapy on the sagittal pharyngeal dimensions in Class II subjects. Int. J. Pediatr. Otorhinolaryngol. 2017, 101, 47-50. [CrossRef] [PubMed]

46. Rizk, S.; Kulbersh, V.P.; Al-Qawasmi, R. Changes in the oropharyngeal airway of Class II patients treated with the mandibular anterior repositioning appliance. Angle Orthod. 2016, 86, 955-961. [CrossRef] [PubMed]

47. Rongo, R.; Martina, S.; Bucci, R.; Festa, P.; Galeotti, A.; Alessandri Bonetti, G.; Michelotti, A.; D’Antò, V. Short-term effects of the Sander bite-jumping appliance on the pharyngeal airways in subjects with skeletal Class II malocclusion: A retrospective case-control study. J. Oral Rehabil. 2020. [CrossRef] [PubMed]

48. Ulusoy, C.; Canigur Bavbek, N.; Tuncer, B.B.; Tuncer, C.; Turkoz, C.; Gencturk, Z. Evaluation of airway dimensions and changes in hyoid bone position following class II functional therapy with activator. Acta Odontol. Scand. 2014, 72, 917-925. [CrossRef] [PubMed]

49. Papageorgiou, S.N.; Koletsi, D.; Eliades, T. What evidence exists for myofunctional therapy with prefabricated appliances? A systematic review with meta-analyses of randomised trials. J. Orthod. 2019, 46, $297-310$. [CrossRef]

50. Schwab, R.J.; Gupta, K.B.; Gefter, W.B.; Metzger, L.J.; Hoffman, E.A.; Pack, A.I. Upper airway and soft tissue anatomy in normal subjects and patients with sleep-disordered breathing. Significance of the lateral pharyngeal walls. Am. J. Respir. Crit. Care Med. 1995, 152, 1673-1689. [CrossRef]

51. Schwab, R.J.; Gefter, W.B.; Hoffman, E.A.; Gupta, K.B.; Pack, A.I. Dynamic upper airway imaging during awake respiration in normal subjects and patients with sleep disordered breathing. Am. Rev. Respir. Dis. 1993, 148, 1385-1400. [CrossRef]

52. Poole, M.N.; Engel, G.A.; Chaconas, S.J. Nasopharyngeal cephalometrics. Oral Surg. Oral Med. Oral Pathol. 1980, 49, 266-271. [CrossRef]

53. Schütz, T.C.; Dominguez, G.C.; Hallinan, M.P.; Cunha, T.C.; Tufik, S. Class II correction improves nocturnal breathing in adolescents. Angle Orthod. 2011, 81, 222-228. [CrossRef] [PubMed]

54. Cozza, P.; Baccetti, T.; Franchi, L.; De Toffol, L.; McNamara, J.A., Jr. Mandibular changes produced by functional appliances in Class II malocclusion: A systematic review. Am. J. Orthod. Dentofac. Orthop. 2006, 129, 599.e1-599.e12. [CrossRef] [PubMed]

55. Havakeshian, G.; Koretsi, V.; Eliades, T.; Papageorgiou, S.N. Effect of Orthopedic Treatment for Class III Malocclusion on Upper Airways: A Systematic Review and Meta-Analysis. J. Clin. Med. 2020, 9, 3015. [CrossRef]

56. Papageorgiou, S.N.; Cobourne, M.T. Data sharing in orthodontic research. J. Orthod. 2018, 45, 1-3. [CrossRef]

57. Papageorgiou, S.N.; Xavier, G.M.; Cobourne, M.T. Basic study design influences the results of orthodontic clinical investigations. J. Clin. Epidemiol. 2015, 68, 1512-1522. [CrossRef]

58. Papageorgiou, S.N.; Koretsi, V.; Jäger, A. Bias from historical control groups used in orthodontic research: A meta-epidemiological study. Eur. J. Orthod. 2016, 39, 98-105. [CrossRef]

59. Cappelleri, J.C.; Loannidis, J.P.A.; Schmid, C.H.; De Ferranti, S.D.; Aubert, M.; Chalmers, T.C.; Lau, J. Large Trials vs. Meta-analysis of Smaller Trials. JAMA 1996, 276, 1332-1338. [CrossRef]

60. Papageorgiou, S.N.; Höchli, D.; Eliades, T. Outcomes of comprehensive fixed appliance orthodontic treatment: A systematic review with meta-analysis and methodological overview. Korean J. Orthod. 2017, 47, 401-413. [CrossRef]

61. Konstantonis, D.; Vasileiou, D.; Papageorgiou, S.N.; Eliades, T. Soft tissue changes following extraction vs. nonextraction orthodontic fixed appliance treatment: A systematic review and meta-analysis. Eur. J. Oral Sci. 2018, 126, 167-179. [CrossRef]

62. Battagel, J.M.; Johal, A.; Smith, A.M.; Kotecha, B. Postural variation in oropharyngeal dimensions in subjects with sleep disordered breathing: A cephalometric study. Eur. J. Orthod. 2002, 24, 263-276. [CrossRef] [PubMed] 
63. Hsu, W.E.; Wu, T.Y. Comparison of upper airway measurement by lateral cephalogram in upright position and CBCT in supine position. J. Dent. Sci. 2019, 14, 185-191. [CrossRef] [PubMed]

64. Eslami, E.; Katz, E.S.; Baghdady, M.; Abramovitch, K.; Masoud, M.I. Are three-dimensional airway evaluations obtained through computed and cone-beam computed tomography scans predictable from lateral cephalograms? A systematic review of evidence. Angle Orthod. 2017, 87, 159-167. [CrossRef] [PubMed]

Publisher's Note: MDPI stays neutral with regard to jurisdictional claims in published maps and institutional affiliations.

(C) 2020 by the authors. Licensee MDPI, Basel, Switzerland. This article is an open access article distributed under the terms and conditions of the Creative Commons Attribution (CC BY) license (http://creativecommons.org/licenses/by/4.0/). 